\title{
Was the obstetric care negligent? Judgement and comments
}

The above case is reported on pages 117-121 of this issue. The judgement which was delivered, and Dr Catherine James' own comments on the case are given below.

\section{The judgement}

Having heard all the evidence the judge found in favour of the defendants, he expressed the view that neither the doctors nor the midwives had been negligent in their care of Mrs A. in that they had acted in accordance with a responsible body of currently held medical opinion in their dealings with the patient.

The question of damages did not therefore arise but the figure put forward by the plaintiff's advisers before the trial was approximately $£ 600,000$ and the defendant's counsel considered that the judge, were he to have found for the plaintiff, might well have awarded in the region of $£ 450,000-£ 500,000$.

\section{Author's comments on the case}

It is extremely difficult to diagnose labour prospectively particularly when cervical assessment by vaginal examination is contraindicated, as in this case. It is always easy to be wise after the event but a doctor must do what he thinks is in his patient's best interests based upon the facts available to him at the time. To have taken active steps to deliver Mrs A. by what would almost certainly have been a classical caesarean section at twenty seven and a half weeks gestation when her symptoms and signs were essentially little different to those over the preceding weeks would have been a courageous and many would argue a quite unjustifiable decision since it posed substantial risk not only to the life of the baby but also to that of the mother. Because he found that the defendants had not been negligent the judge did not have to deal with the causation argument but it is likely, on the evidence put forward, that the defendants' argument would have been preferred, namely that the child's cerebral palsy resulted from her extreme prematurity rather than any failure on behalf of Mrs A.'s medical attendants.

Most people will feel saddened that this severely handicapped child could not receive financial compensation to help her cope with her disabilities for what may be many years to come. As English law stands at present a patient can only be 
compensated where his or her damage has been caused by negligence, which the judge did not find to be the case here. The "Crown Indemnity" principle recently introduced in the United Kingdom will not alter this situation since the legal process for claims arising out of hospital treatment within the National Health Service remains the same, the difference being that each district health authority will now pay any damages awarded in full and will no longer look to the doctors' defence organisations for reimbursement in respect of their members' involvement.

Even under a no fault scheme the child would not have received compensation because it is likely that her disability would be considered to have arisen from a natural obstetric complication rather than from a medical accident. 